\title{
The Electrical Breakdown of PVC and PMMA Barrier in Oil Insulator under Non-Uniform Field
}

\author{
Surapong Seela-or ${ }^{1, a}$, Kittipong Tonmitr ${ }^{1, b}$ and Arkom Kaewrawang ${ }^{1, c}$ \\ ${ }^{1}$ Department of Electrical Engineering, Faculty of Engineering, Khon Kaen University, \\ Khon Kaen 40002, Thailand \\ apinee1987@gmail.com, ${ }^{\text {b } k i t t o n @ k k u . a c . t h, ~}{ }^{c}$ arkom@elec.kku.ac.th
}

Keywords: Electrical breakdown, Non-uniform field, PVC, PMMA, Solid insulator

\begin{abstract}
This paper presents breakdown test of Polyvinyl chloride hard (PVC), Polymethyl methacrylate (PMMA) under non-uniform electric field in transformer oil. PVC and PMMA are placed between point-plate electrodes. The result of the experiment shows that the breakdown voltage of point-plate electrodes is lower than point-point electrodes. PVC endures more breakdown voltage than PMMA. The breakdown voltage of transformer oil with double barriers placed close to electrode is maximum value at $216.5 \mathrm{kV}$ and it is higher than that for single barrier of $205 \mathrm{kV}$. The results of the experiment can be used to design the blockage room between the conductor and ground in the transformer oil which has the limit space and can endure high breakdown voltage, and it suits the non-uniform electric field characteristics as well.
\end{abstract}

\section{Introduction}

The insulation in high voltage system works as the blockage between the conductors which has different voltage or between the conductors and ground. The solid and liquid insulation can be used together. There are widely used in high voltage systems, especially with the transformer oil, high voltage cable, capacitor and circuit breaker [1].

The transformer oil is the liquid insulation [2]. It has good properties on heat transfer, inflammable and it can quench the electric arc. When breakdown occurs, it can recover its insulation properties [3]. However, its insulation properties will be lower, and it can endure the electric field of $10-25 \mathrm{kV} / \mathrm{mm}$, it has the electrical resistively of $10^{13}-10^{14} \Omega / \mathrm{cm}$ at $20^{\circ} \mathrm{C}$ and the permittivity of 2.2 [4].

The solid insulator [5] should endure high breakdown voltage as the small materials should endure high mechanical in order to support weight, torsion, inflammable, nontoxic when it is burned. However, when breakdown occurs, it permanently loses insulation and cannot recover its insulation properties.

This research investigate on the endurance to the breakdown voltage of PVC and PMMA. They were placed between the electrodes in the transformer oil of the non-uniform electric field by testing two cases: point-point and point-plate by placing PVC and PMMA in two characteristics: (i) dielectric barrier with $2 \mathrm{~mm}$ thickness placed between electrodes (ii) two sheets dielectric barrier with $1 \mathrm{~mm}$ thickness placed closely between two electrodes. The damage zones from breakdown voltage can be observed by using a microscope after breakdown.

\section{Equipment Setup}

Electrode is made from brass and there are two types: (i) point type which has $20 \mathrm{~mm}$ of diameter with the $60^{\circ}$ of sharp tip (ii) plate types which has $60 \mathrm{~mm}$ of diameter with $1 \mathrm{~mm}$ thickness. Two types of electrodes are tested, point-point and point-plate with $5 \mathrm{~mm}$ gap between electrodes as shown in Fig. 1. 


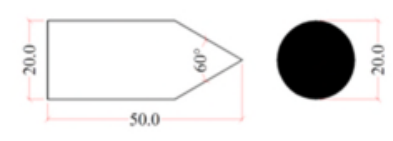

(a) Point electrode

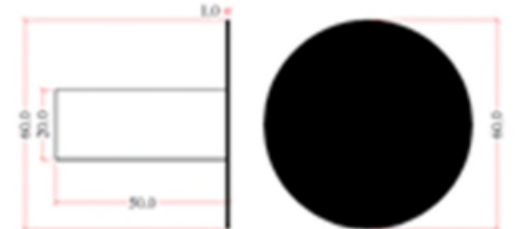

(b) Plate electrode

Fig. 1 Electrode configuration (dimensions in $\mathrm{mm}$ ).

PVC and PMMA blocked between electrodes have $130 \mathrm{~mm}$ wide and $180 \mathrm{~mm}$ long. It has a smooth skin placed between 2 types as shown in Fig. 2 and 3.

Single barrier: Dielectric barrier has the thickness of $2 \mathrm{~mm}$ placed in the middle with the electrode spacing of $1.5 \mathrm{~mm}$.

Double barrier: Dielectric barrier has the thickness of $1 \mathrm{~mm}$. Two sheets are placed near the ground and high voltage electrodes with the electrode spacing of $3 \mathrm{~mm}$.

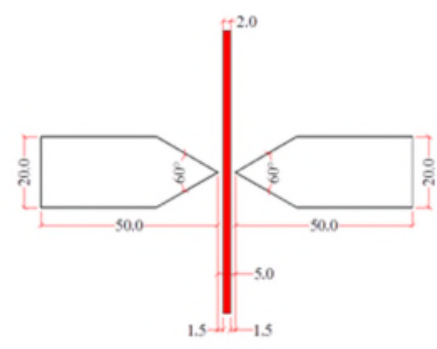

(a) Single barrier

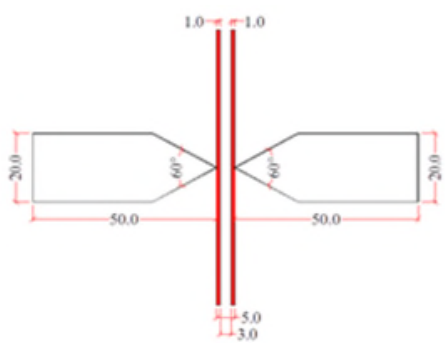

(b) Double barrier

Fig. 2 Point-point electrode and PVC and PMMA configuration (dimensions in $\mathrm{mm}$ ).

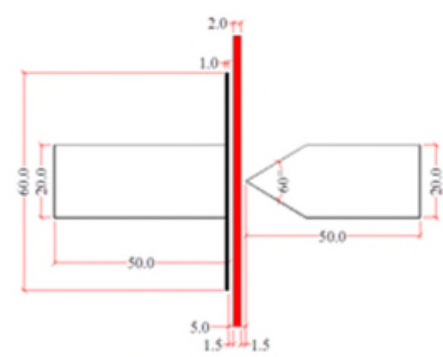

(a) Single barrier

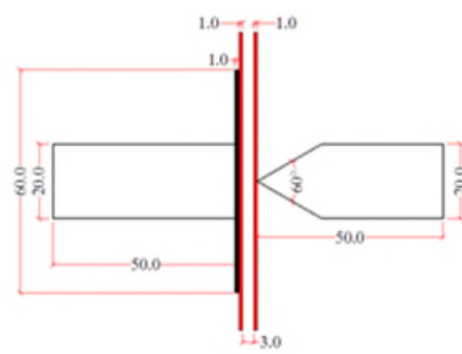

(b) Double barrier

Fig. 3 Point-plate electrode and PVC and PMMA configuration (dimensions in mm).

The breakdown test of PVC and PMMA in transformer oil by using PTT Hivolt 99 transformer oil in the test. The environmental control in the test is the same condition: the operating room temperature is at $28{ }^{\circ} \mathrm{C}$, temperature of transformer oil at $30^{\circ} \mathrm{C}$, atmosphere pressure at $745 \mathrm{mmHg}$, and 78\% humidity. The high voltage direct current (HVDC) is applied to the electrodes and increased with the voltage rates of $2 \mathrm{kV} / \mathrm{s}$ until breakdown occurs at the electrode and dielectric barrier. After breakdown occurs, leave it for $20 \mathrm{~min}$. to make the transformer oil to reform to be the insulator. The equipment details are shown in Fig. 4.

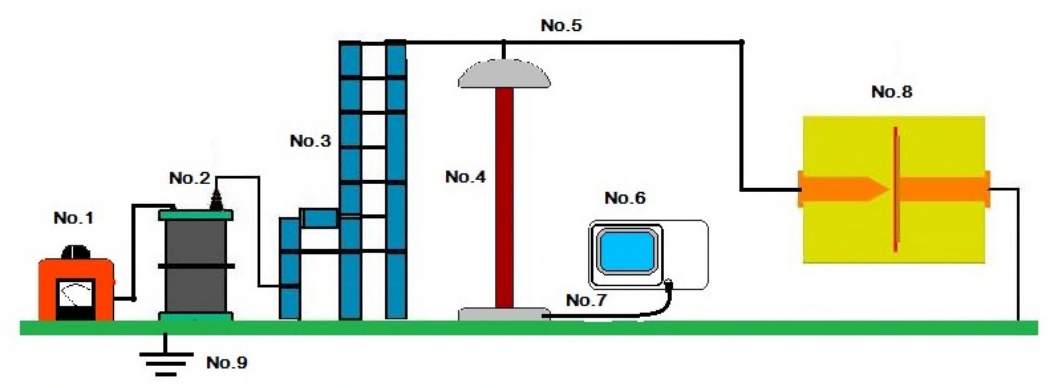

Fig. 4 Equipment setup. 
Apparatus for HVDC test:

No.1 Slide voltage regulator of $0-230 \mathrm{~V}, 10 \mathrm{~A}$

No.2 Transformer $200 \mathrm{~V} / 68 \mathrm{kV}$

No.3 HVDC generator of 0-400 kV

No.4 R-C-R voltage (Hipotronics) divider ratio 1:609 for HVDC test

No.5 Aluminum bus-bar diameter of $25 \mathrm{~mm}$

No.6 Oscilloscope (Tektronix 2212, $60 \mathrm{MHz}$ )

No.7 Coaxial RG6U Oscilloscope signal

No.8 Chamber vessel for breakdown voltage test set

No.9 Ground

The damage area of the dielectric barrier will be observed by USB microscope, it has an optical zoom of $20 x-800 x$.

\section{Results and Discussions}

The results of the experiments can be classified into two cases as follows:

The Breakdown Voltage of PVC and PMMA. The breakdown voltage of the dielectric barrier tests under HVDC. The results of the breakdown of PVC and PMMA blocked between point-point and point-plate electrodes in transformer oil are shown in Table 1.

Table 1. Experimental results of PVC and PMMA breakdown voltage (in $\mathrm{kV}$ ) in the transformer oil.

\begin{tabular}{|c|c|c|c|c|}
\hline \multirow{2}{*}{$\begin{array}{c}\text { Dielectric } \\
\text { barrier }\end{array}$} & \multicolumn{2}{|c|}{ point-point } & \multicolumn{2}{c|}{ point-plate } \\
\cline { 2 - 5 } & Single barrier & Double barrier & Single barrier & Double barrier \\
\hline PVC & 205.0 & 216.5 & 183.5 & 195.7 \\
\hline PMMA & 135.5 & 182.7 & 132.2 & 179.7 \\
\hline
\end{tabular}

Fig. 5 (a) shows the breakdown voltage of point-point electrode. We found that the breakdown voltage of transformer oil with PVC - single and double barriers are 205.0 and $216.5 \mathrm{kV}$, respectively. By placing PMMA - single and double barriers, the breakdown voltage are 134.5 and $182.7 \mathrm{kV}$, respectively. Therefore, the breakdown voltage for double barrier is higher than that for single barrier.

The breakdown voltage of point-plate electrode is shown in Fig. 5 (b). We discovered that the breakdown voltage for double barrier is higher than that for single barrier. The breakdown voltage of the transformer oil with PVC - single and double barriers are 183.5 and $195.7 \mathrm{kV}$, respectively. By placing PMMA - in single and double barriers are $132.5 \mathrm{kV}$ and $179.7 \mathrm{kV}$.

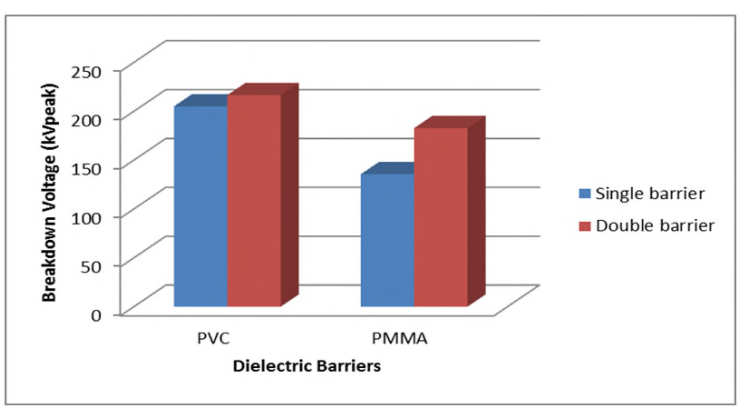

(a) Point-point electrode

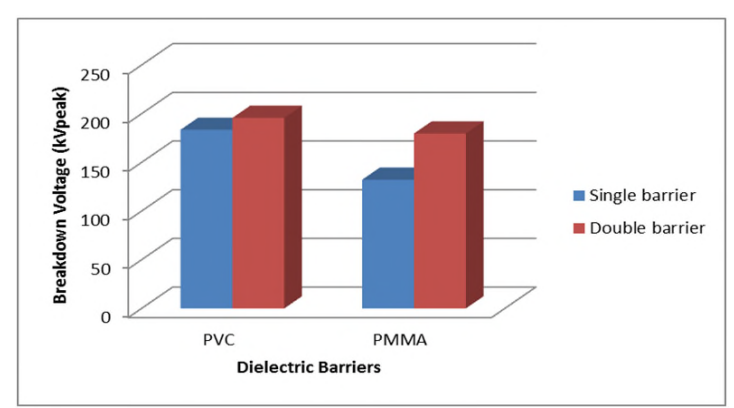

(b) Point-plate electrode

Fig. 5 Breakdown voltages for PVC and PMMA.

The damage zones have been observed by using USB Microscope camera with 20X 800X magnifiers after breakdown. PVC has more damage zones than PMMA, but it has similar damage characteristic. Its damages look like a small hole. In addition, there were some cracks occurred around the edge which depends on the different breakdown voltages and the endurance of PVC and PMMA as shown in the Fig. 6 and Fig. 7. 


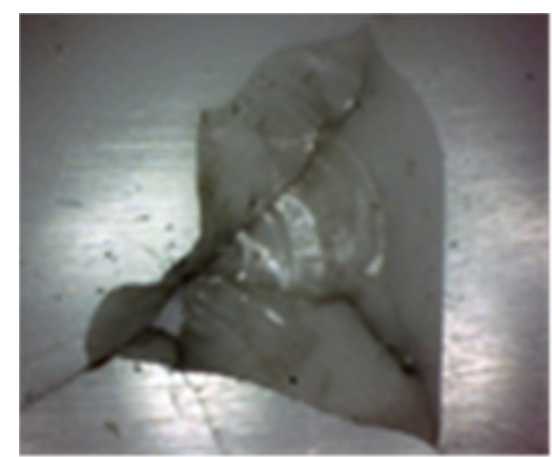

(a) Point-point electrode

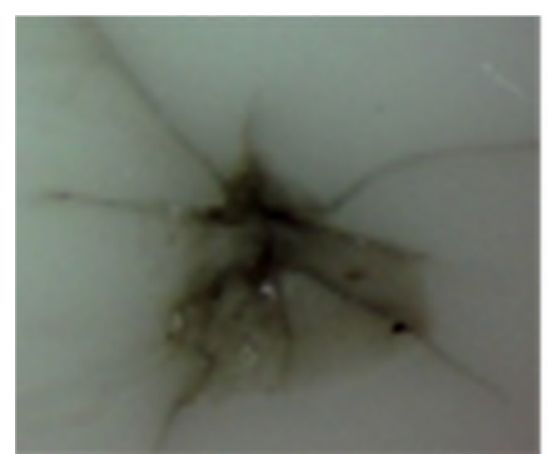

(b) Point-plate electrode

Fig. 6 Photograph of PVC after breakdown in the transformer oil.

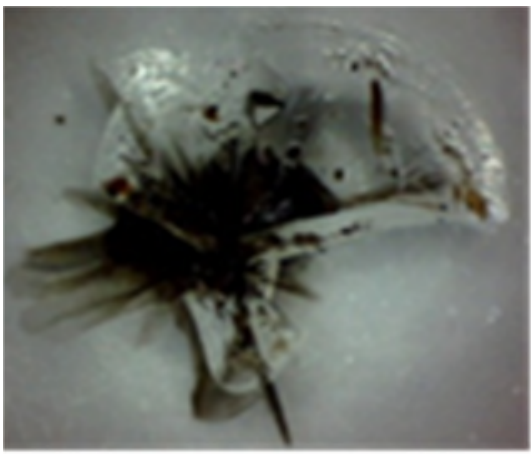

(c) Point-point electrode

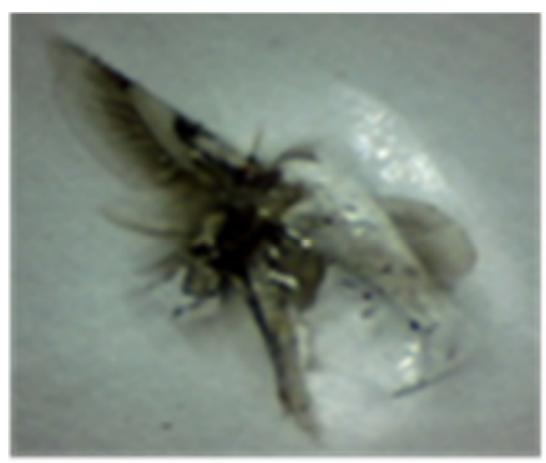

(d) Point-plate electrode

Fig. 7 Photograph of PMMA after breakdown in the transformer oil.

From the breakdown voltage test of PVC and PMMA blocked between electrodes in the transformer oil, PVC endures more breakdown voltage than PMMA. The breakdown voltage in the case of point-point electrodes is higher than that for point-plate electrode. By placing double barrier, it endures higher breakdown voltage than single barrier because of the insulator material endurance electric filed characteristics and different forms of placing dielectric barrier.

The Breakdown Voltage of Transformer Oil and Air. Table 2 shows the breakdown voltage test under HVDC in the case of no dielectric barrier between electrodes at the gap of 5-30 mm presented in this sub-section.

Table 2. Experiment results of breakdown voltage air and transformer oil.

\begin{tabular}{|c|c|c|c|c|}
\hline \multirow{2}{*}{$\begin{array}{c}\text { Gap } \\
(\mathrm{mm})\end{array}$} & \multicolumn{3}{|c|}{ Breakdown voltage $\left(\mathrm{kV}_{\text {peak }}\right)$} \\
\cline { 2 - 5 } & \multicolumn{2}{|c|}{ Transformer oil } & \multicolumn{2}{c|}{ Air } \\
\cline { 2 - 5 } & point-point & point-plate & point-point & point-plate \\
\hline 5 & 24.8 & 24.3 & 9.1 & 10.2 \\
\hline 10 & 37.5 & 47.7 & 9.8 & 15.7 \\
\hline 15 & 46.9 & 67.0 & 12.6 & 24.8 \\
\hline 20 & 54.8 & 88.6 & 13.2 & 30.4 \\
\hline 25 & 72.3 & 97.2 & 21.3 & 35.8 \\
\hline 30 & 92.6 & 112.3 & 25.0 & 42.3 \\
\hline
\end{tabular}

When the electrode gap increases, the breakdown voltage of transformer oil and air increases as shown in Fig. 8. It was found that the transformer oil endures the higher breakdown voltage than air. The breakdown voltage of point-plate electrode in the transformer oil is the highest of $112.3 \mathrm{kV}$ and point-point electrode of $92.5 \mathrm{kV}$ at $30 \mathrm{~mm}$. The breakdown voltage of air with point-plate and point-point electrodes at $30 \mathrm{~mm}$ is 42.3 and $25 \mathrm{kV}$, respectively. The point-point and point-plate electrodes have the different breakdown voltages owing to the different shapes of electrodes. 


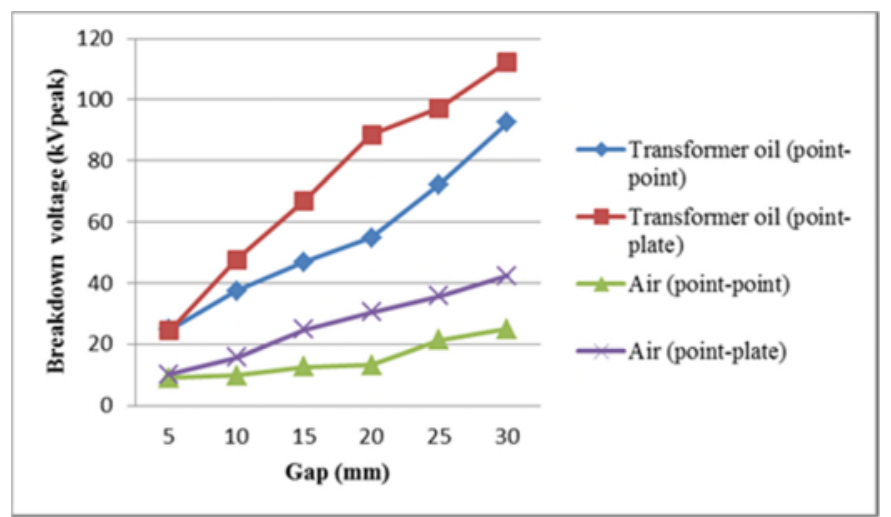

Fig. 8 Breakdown voltage in transformer oil and air with point-point and point- plate electrodes.

For the breakdown voltage of PVC and PMMA in the transformer oil, PVC and PMMA can be used to block between the conductor and ground. In the case of pure transformer oil the breakdown voltage of $24.8 \mathrm{kV}$ at the gap of $5 \mathrm{~mm}$. On the other hand, the breakdown voltage of PVC and PMMA is 216.5 and $182.7 \mathrm{kV}$, respectively. Therefore, PVC and PMMA have a high breakdown voltage they cannot recover their insulation properties after breakdown. However, the transformer oil can recover its insulation properties after breakdown.

\section{Conclusion}

The endurance of breakdown voltage for the transformer oil with PVC and PMMA under non-uniform electric field by using point-point and point-plate electrodes is investigated in this paper. The PVC endures more breakdown voltage than PMMA. In the case of placing double barriers of PVC with a thickness of $1 \mathrm{~mm}$ between point-point electrodes, it can endure breakdown voltage of $216.5 \mathrm{kV}$, that is higher than placing single barrier with a thickness of $2 \mathrm{~mm}$ between electrodes endured breakdown voltage of $205 \mathrm{kV}$. Placing dielectric barrier blocked between point-point electrode endures the higher breakdown than that for point-plate. The breakdown voltage depends on the insulator material endurance, electric field characteristic and placing form of PVC and PMMA. The results of the experiment can leads to design the solid insulator which is effectively capable to use in high voltage equipment with withstanding the high voltage non-uniform field stress.

\section{Acknowledgement}

The authors wish to thanks KKU High Voltage Engineering Research Laboratory at Department of Electrical Engineering, Khon Kaen University, Khon Kaen, Thailand who has supported all the equipments.

\section{References}

[1] J. Dai, Z. D. Wang and P. Jarman, Creepage Discharge on Insulation Barriers in Aged Power Transformers, IEEE T. Dielect. El. In. 17(4) (2010) 1327-1335.

[2] G. Chen and M. H. Zuber, Pre-breakdown Characteristics of Contaminated Power Transformer Oil, Electr. Insul. M. IEEE Publication. 21 (2007) 659-662.

[3] A. S. Gill, The Design of Transformer Oil, IEEE International Symposium on Electrical Insulation, USA 2000.

[4] A. G. Siemens, Electrical Engineering Handbook, 1981.

[5] A. Kara, Ö. Kalenderli and K. Mardikyan, Electrostatic Analysis of DC Discharge Phenomena in Air with Dielectric Barriers, International Conference on Advancements in Electronics and Power Engineering (ICAEPE'2011) Bangkok 2011. 